\begin{tabular}{|llll}
\hline International Journal of Applied & $\mathbf{A}$ & $\mathbf{I}$ \\
\hline
\end{tabular}

Research Article

\title{
Effects of the Number of Rules on the Quality of Fuzzy Logic Control of Induction Motor
}

\author{
Zainab Yunusa $^{1,2, *}$, Ado Dan-Isa ${ }^{2 \dagger}$, Yunusa Ali Sai'd ${ }^{1,3}$, Reza Shoorangiz ${ }^{1}$
}

(1) Department of Electrical and Electronics Engineering, Faculty of Engineering, Universiti Putra Malaysia, 43400 UPM Serdang, Selangor, Malaysia.

(2) Department of Electrical Engineering, Bayero University, Kano, Nigeria.

(3) Electrical and Electronic Engineering Department, Collage of Engineering, Kaduna Polytechnic, Kaduna, Nigeria.

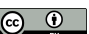

\section{Article history:}

Received 01 May 2013

Reviewed 22 May 2013

Revised 08 July 2013

Accepted 14 July 2013

Published 17 July 2013

\begin{abstract}
This article reports on the investigation into the relationship between the number of rules for a triangular membership functions and quality of control of induction motor. To achieve this aim, a fuzzy logic controller was designed using the Fuzzy logic toolbox in MATLAB SIMULINK with 3, 5 and 7 rule based triangular membership functions respectively. A $50 \mathrm{HP}, 460 \mathrm{~V}, 3-$ phase induction motor was used as the plant for the speed control. The FLC was incorporated into the SIMULINK model of MATLAB toolbox and simulation was carried out, response curves at the rated speed of 120 and $140^{\mathrm{rad} / \mathrm{sec}}$ at no-load were observed together with the stator currents curves respectively. The quality of the controller is defined by the performance indicators in the form of peak overshoot and settling time of the Fuzzy logic controller.
\end{abstract}

Keywords: Induction motor, Fuzzy Logic Controller, Membership function, Robotic, Control.

\section{Introduction}

The numerous advantages exhibited by Alternating Current (AC) motors especially the Squirrel Cage Induction Motor (SCIM) have made them suitable candidates for industrial applications. Amongst these advantages are high reliability, cheaper in terms of cost and easyfree maintenance electrical drives. However, the main drawback of using AC induction motor is the difficulty in control which is due to the non-linear behaviour of the motor. This characteristic also makes the mathematical modelling of the motor rather difficult. Due to a number of modern manufacturing processes that require variable speed several conventional control methods are used to offer speed control. Different control techniques have been used to control AC induction motors like the direct torque control ${ }^{[1-4]}$, Indirect field oriented control ${ }^{[5,6]}$, etc. However, the main limitation of the conventional electric motor control is the complexity of the mathematical model due to the non-linearities associated with the voltage and current equations. As an alternative the use of fuzzy logic control, which is a member of the soft computing techniques, has been used by ${ }^{[7]}$ Afonso et al. to control the speed of a three phase induction motor. Fuzzy logic technique has also been used to design self-tuning PI control [9] and vector control of induction motor ${ }^{[8]}$.

\footnotetext{
* Corresponding author \#1: Z. Yunusa

ø: +6 0182325483

$\bowtie:$ zee1yunusa@yahoo.com

${ }^{\dagger}$ Corresponding author \#2: A. Dan-Isa

$凶$ : danisa@buk.edu.ng
}

The idea of Fuzzy logic control was initiated by Zadeh in $1965^{[9]}$. Since then it has been embedded into so many applications due to the its application in non-linear systems that have complex mathematical models. The beauty of using fuzzy logic control is that effective control is possible even in the absence of a mathematical model. The knowledge of a human operator is captured in form of a rule base by means of which the control variable is determined. This interesting property and that the control could be done even in the absence of a mathematical model of the plant called into the investigation into the quality of control that can be realized from fuzzy logic. However, this does not seem to have been sufficiently investigated by researchers. El-Arabawy et al. ${ }^{[10]}$ studied the effect of the number of membership functions (MF) on the stability of fuzzy logic control of induction motor. The simulation results showed that the number of membership functions has no effect on the stability boundary of the fuzzy logic control system. Purwanto et al. ${ }^{[8]}$ also investigated the application of Fuzzy Logic Controller (FLC) on 3-phase induction motor speed control by changing the parameters of a triangular membership function. Their results show that symmetrical triangular membership functions give better control quality in terms of settling-time, overshoot and steady-state error. In the work of Aras et al. ${ }^{[11]}$ a comparison on the number of rules for the FLC was made between a $3 \times 3$ and a $5 \times 5$ rule matrix for Direct Current (DC) control speed motor. Results obtained showed that the $5 \times 5$ rulematrix FLC produce better and more accurate results. The last three cited references were all based on trian- 
gular membership functions. Gayathri Monicka et al. ${ }^{\text {[12] }}$ reported about the effects of various types of membership functions (triangular, trapezoidal, Gaussian, Bell-shape) in the control of an induction motor using fuzzy logic and concluded that triangular membership function produces controllers that reduce steady state error more than the other three shapes.

For the design of an effective controller, It is very important for the designer to have knowledge on the optimal stability of the plant's controller so that engineers in the field of control and robotics will know the factors that influence the performance of their FLC. It therefore becomes very imperative to investigate the relationship that exists if any between the number of fuzzy rules and the effectiveness and/quality of the controller. Based on the reviewed literature, it was observed that not much have been done on the induction motor but only on DC motor as reported by ${ }^{[13]}$ which is closely related to our work in which they investigated the effects of the number of rule matrix in DC motor.

In this work, it is proposed to design an FLC using $3 \times 3$, $5 \times 5$ and $7 \times 7$ rule based triangular membership function to control an induction motor so as to investigate the effects the number of rules has on the quality of the fuzzy logic controller. Also it attempts to extend this rule-base from $5 \times 5$ to $7 \times 7$ matrix so as to compare which gives the best output in terms of the performance indicators.

\section{Methodology}

The design of the fuzzy controller consists of three steps:

1. Fuzzification

2. Inference

3. Defuzzification

Thus each of the inputs will be fuzzified individually and the set of fuzzified inputs is used for the fuzzy processing. In the fuzzy processing or fuzzy inference engine a set of rules are set which are used to map a given inputs into a given outputs. The set of fuzzy outputs is then converted into a crisp output in the defuzzification process. This is shown in Fig. 1.

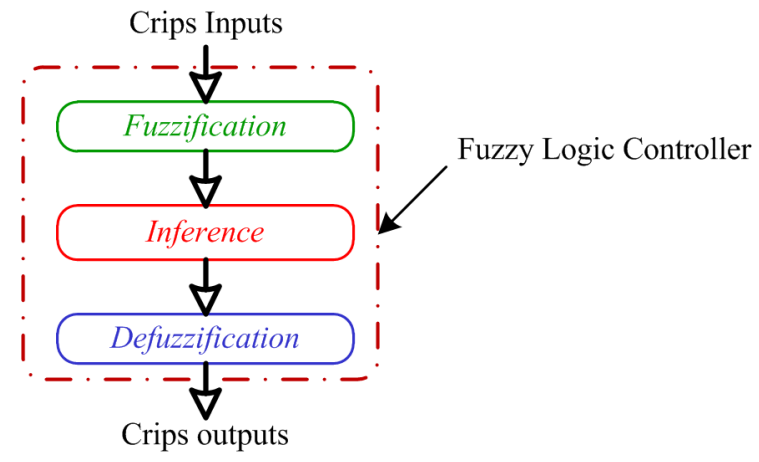

Fig. 1. Design steps for a FLC

The FLC in this work is designed using different number of triangular membership functions with $3 \times 3,5 \times 5$ and $7 \times 7$ rule matrices respectively to control the speed of a $50 \mathrm{HP}, 460 \mathrm{~V}, 4-$ pole, $60 \mathrm{~Hz}$ and 3-phase induction motor. This is the induction motor model that comes with Simulink 7.0.4 in MATLAB. The induction motor model was ran at no-load at a rated speeds of 120 and $140 \mathrm{rad} / \mathrm{sec}$ with different fuzzy logic controllers designed for the 3,5
Table 1. Fuzzy rules formulation for 7 MF FLC

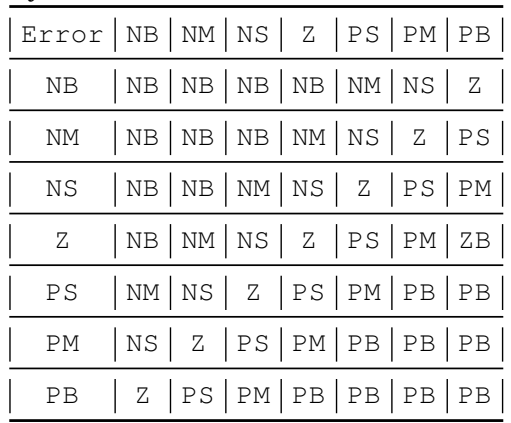

and 7 MFs respectively. The model would was monitored for the responses of the speed, torque, armature current and voltages.

\subsection{Membership Function Design}

A membership function curve describes the degree of belonging to a fuzzy set. Each of the input point in the universe of discourse is assigned a membership value between 0 and 1 . These values are called the degree of membership $\mu$. The triangular membership function was selected for the inputs and the output variables as represented in Fig. 2. The crisp inputs to the FLC are error and change in error while our crisp output is the torque.

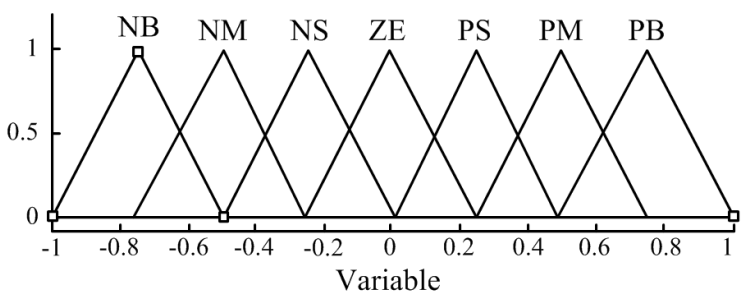

Fig. 2. $7 \times 7$ matrix triangular membership functions

For the case of the $7 \times 7$ rule-based-membership functions, the universe of discourse is divided into 7 fuzzy sets so as to represent the $7 \mathrm{MF}$ FLC. The seven linguistic variables used are Negative Big (NB), Negative Medium (NM), Negative Small (NS), Zero (Z), Positive Small (PS), Positive Medium (PM) and Positive Big (PB). A $7 \times 7$ rulematrix was constructed to form 49 cells as represented in Table 1.

Similarly, the 3 and $5 \mathrm{MF}$ designs were also carried out in a similar fashion. For the 3 rules we have a $3 \times 3$ matrix yielding 9 cells while for the case of 5 rules we have a $5 \times 5$ matrix yielding a total number of 25 cells respectively.

\subsection{Fuzzy Rules Formulation}

The rules of the fuzzy controller were formed using the IF-THEN rules. The error and change in error were chosen as inputs while the output is the control torque. The rules were formulated with the help of Table 1 . For the case of the 7 MFs we have a total of 49 rules and for the $5 \mathrm{MF}$ we have a total of 25 rules and similarly for the case of the $3 \mathrm{MF}$ we have a total of 9 rules.

\subsection{Defuzzification}

Different techniques are used for the defuzzification. In this work the centre of height technique was used for the computation of the crisp value of the output. This technique requires the evaluation of the centroid of the membership function for each output. Then, the output 
is later computed as the average of each centroids which are weighted according to their heights. Equation (1) has been adopted from Saade and Diab ${ }^{[14]}$.

$$
T=\frac{\sum_{i=1}^{n} \mu\left(x_{i}\right) x_{i}}{\sum_{i=1}^{n} \mu\left(x_{i}\right)}
$$

where $n$ is the number of discrete values $x_{i}$ on the universe of discourse. $\mu$ is the membership grade of the element $x_{i}$ in the universe of discourse.

\section{Results}

After the fuzzy logic controllers were designed, the IM model in the SIMULINK of MATLAB was used to carry out the simulation. The model was used in MATLAB to demonstrate PI control of an IM. For the purpose of this investigation the PI controller in the model was replaced with the designed FLCs and the motor was run at without load and at rated speed of $120^{\mathrm{rad}} / \mathrm{sec}$. The simulation was run for a period of 3 seconds. The simulation results obtained are shown in Fig. 3, Fig. 4 and Fig. 5. Each graph has the speed (Fig. 3), torque (Fig. 4), and stator currents (Fig. 5) on the y-axis while time (in seconds) is on the $\mathrm{x}$-axis. The response results were obtained for each type of FLC with all conditions constant. The same IM was run again under no-load condition but with the speed changed to $140^{\mathrm{rad}} / \mathrm{sec}$ and the PI controller was replaced with the 3,5 and $7 \mathrm{MFs}$ respectively.

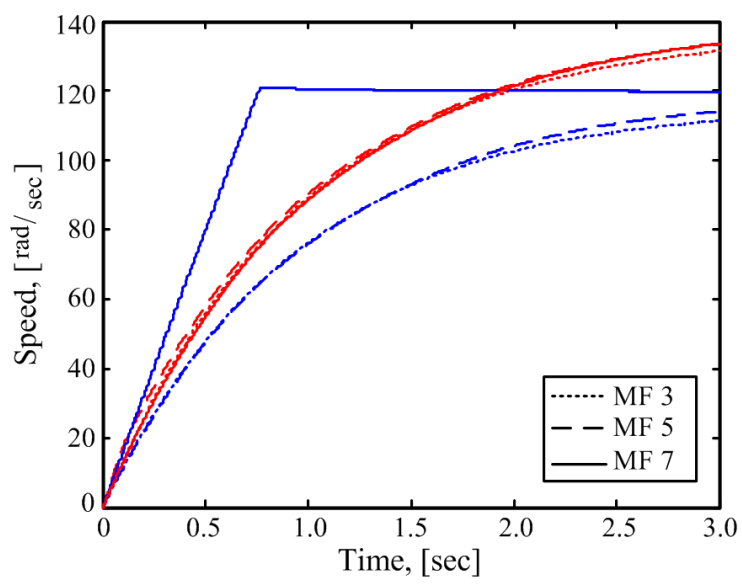

Fig. 3. Speed at no-load for 3, 5 and $7 \mathrm{MF}$ from zero to 120 and $140 \mathrm{rad} / \mathrm{sec}$

\section{Discussions}

Fig. 3 shows the simulation results of the speeds of the IM plotted against time for different types of membership functions at 120 and $140^{\mathrm{rad} / \mathrm{sec}}$ respectively. For a better understanding of the behavior of our FLC. Fig. 3, Fig. 4 and Fig. 5 were used to construct Table 2 based on the responses of the different membership functions and the measure of stability of the controller. Fig. 4 shows a plot of the stator torque versus time for different membership functions and when the induction motor was run at no-load and Fig. 5 shows a plot of stator currents versus time. The performance of the FLC is determined by the performance indicators in terms of the settling time and peak overshoot. From Fig. 3 it could be observed that the $7 \mathrm{MF}$ has the fastest settling time and attained the speed of $120^{\mathrm{rad}} / \mathrm{sec}$ and also in the case of $140^{\mathrm{rad}} / \mathrm{sec}$ the 7 MF FLC showed a closer valve to the rated speed. Fig. 4 shows the graph of torque versus time for different MFs (a)

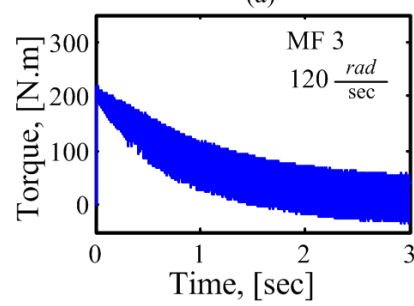

(c)

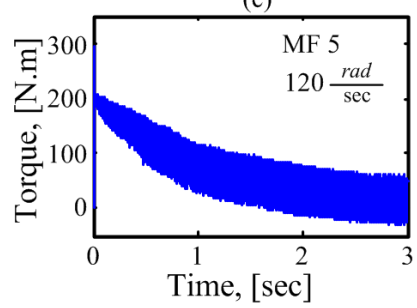

(e)
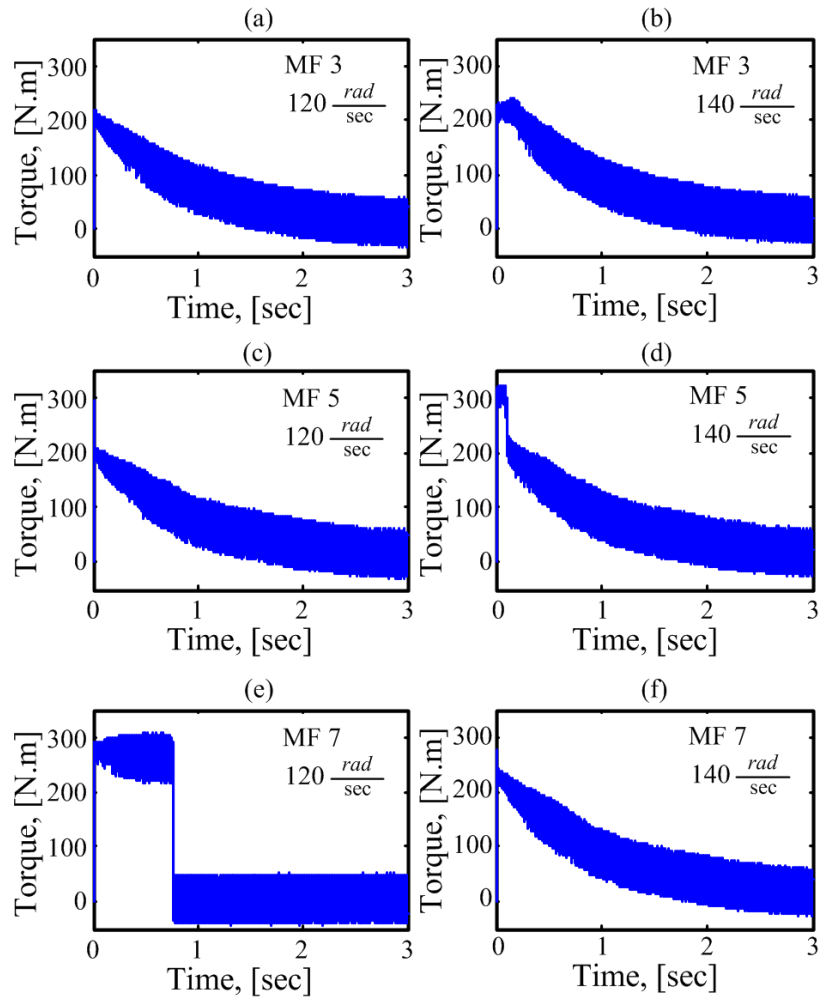

(d)

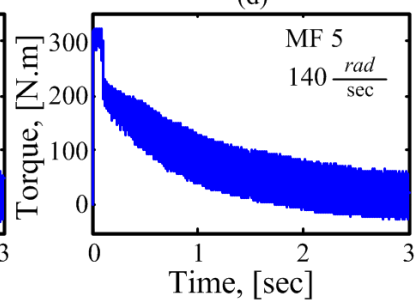

(f)

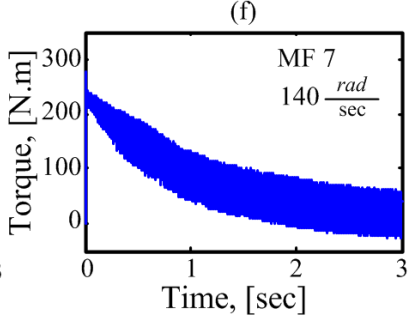

Fig. 4. Torque at no-load for (a) $3 \mathrm{MF}$ and $120^{\mathrm{rad}} / \mathrm{sec}$; (b) $3 \mathrm{MF}$ and $140 \mathrm{rad} / \mathrm{sec}$; (c) $5 \mathrm{MF}$ and $120 \mathrm{rad} / \mathrm{sec}$; (d) $5 \mathrm{MF}$ and $140 \mathrm{rad} / \mathrm{sec}$; (e) $7 \mathrm{MF}$ and $120 \mathrm{rad} / \mathrm{sec}$; and (f) $7 \mathrm{MF}$ and $140 \mathrm{rad} / \mathrm{sec}$

and at no-load. For each MF the response of the torque started at a higher valve between 200 and $300 N . m$ and then attained a steady state valve after a certain time based on the type of membership function. The stability measure which is described by the torque settling time is also summarized in Table 2. Fig. 5 shows a plot of the stator currents versus time for the different membership functions at the rated speeds of 120 and $140 \mathrm{rad} / \mathrm{sec}$. The 3 -phase stator currents started from a peak to peak valve of -200 to $200 \mathrm{~A}$ and finally attained a steady state valve of a peak to peak valve of -60 to $60 \mathrm{~A}$. The measure of stability is also described by the performance indicator of the current settling time. Table 2 summarizes the performance of the FLCs for 3, 5 and $7 \mathrm{MFs}$ at speeds of 120 and $140 \mathrm{rad} / \mathrm{sec}$ respectively. The performance indicators of speed overshoot and settling time of the speed, the torque and the current were shown in percentage and time respectively.

Table 2. IM control at no-load and speed of 120 and $140 \mathrm{rad} / \mathrm{sec}$

\begin{tabular}{l|ll|ll|ll}
\hline Performance Indicator & \multicolumn{2}{|c|}{$3 \mathrm{MF}$} & \multicolumn{2}{c}{$5 \mathrm{MF}$} & \multicolumn{2}{c}{$7 \mathrm{MF}$} \\
\hline Speed & 120 & 140 & 120 & 140 & 120 & 140 \\
\hline Speed overshoot & $5 \%$ & $5 \%$ & $4 \%$ & $4 \%$ & $0 \%$ & $2 \%$ \\
Speed settling time & $2.6 \mathrm{~s}$ & $2.6 \mathrm{~s}$ & $2.5 \mathrm{~s}$ & $2.5 \mathrm{~s}$ & $1 \mathrm{~s}$ & $2.0 \mathrm{~s}$ \\
Torque settling time & $1.5 \mathrm{~s}$ & $1.8 \mathrm{~s}$ & $1.5 \mathrm{~s}$ & $1.7 \mathrm{~s}$ & $0.7 \mathrm{~s}$ & $1.3 \mathrm{~s}$ \\
Current settling time & $1 \mathrm{~s}$ & $1.5 \mathrm{~s}$ & $1 \mathrm{~s}$ & $1.5 \mathrm{~s}$ & $0.7 \mathrm{~s}$ & $0.4 \mathrm{~s}$ \\
\hline
\end{tabular}

With respect to Table 2, it could be seen that the speed overshoot is higher in the case of the 3 and 5 MFs than in the case of $7 \mathrm{MF}$ which has no overshoot. Similarly it could be seen clearly that the settling time is highest for the case of the $3 \mathrm{MF}$ followed by $5 \mathrm{MF}$ but lowest in the case of $7 \mathrm{MF}$. 
(a)

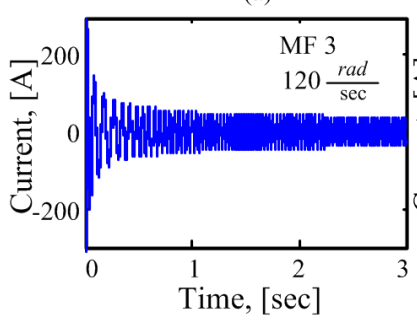

(c)

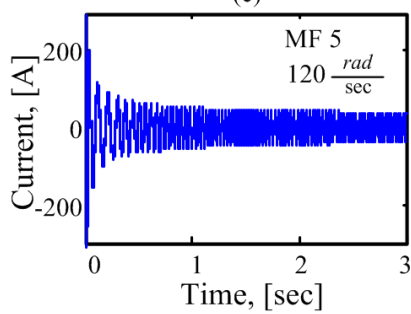

(e)

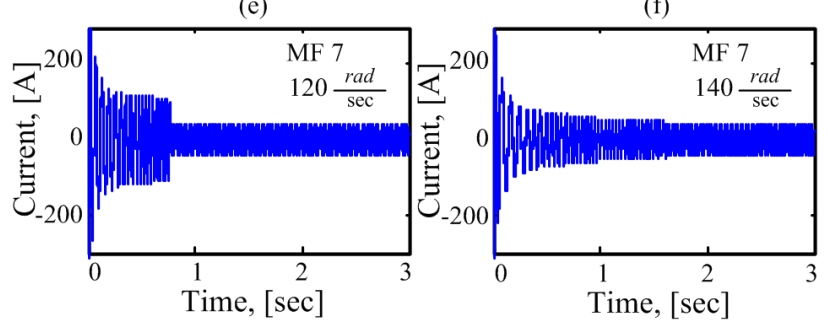

Fig. 5. Current at no-load for (a) $3 \mathrm{MF}$ and $120 \mathrm{rad} / \mathrm{sec}$; (b) $3 \mathrm{MF}$ and $140^{\mathrm{rad}} / \mathrm{sec}$; (c) $5 \mathrm{MF}$ and $120^{\mathrm{rad}} / \mathrm{sec}$; (d) $5 \mathrm{MF}$ and $140^{\mathrm{rad} / \mathrm{sec}}$; (e) $7 \mathrm{MF}$ and $120 \mathrm{rad} / \mathrm{sec}$; and (f) $7 \mathrm{MF}$ and $140^{\mathrm{rad}} / \mathrm{sec}$

\section{Conclusion}

As mentioned earlier, the aim of this work was to find out the relationship that exists if any between the number of membership functions and the stability of the controller which is a measure of the peak overshoot and the settling time which is how fast it takes for the controller to reach steady-state. This helps engineers in field of robotics and control to have insight on the key factors that are necessary for designing a stable system. From the results presented and the discussions it could be deduced that there exists a relationship between the number of membership functions and the stability of the controller. This has been validated from the simulation results obtained when a $50 \mathrm{HP} 3$-phase induction motor was run at no-load and a speed of 120 and $140 \mathrm{rad} / \mathrm{sec}$ respectively. It can therefore be concluded that the higher the number of membership function the more stable the controller. The results for the $7 \times 7$ rule-matrix showed a $0 \%$ overshoot and a faster time to attain steady state. Our results showed significant improvement as compared with works of El-Arabawy et al. ${ }^{[10]}$ and Kimiaghalam et al. ${ }^{[13]}$ because by investigating into effects of the number of rule-based and the effectiveness of the FLC, it was observed that the $7 \times 7$ rule-matrix gave out the best FLC as assessed from the performance indicators. Conclusively, it could be deduced that the higher the number of rules the more effective the controller as justified by the performance indicators.

\section{REFERENCES}

[1] M. Ortega, J. Restrepo, J. Viola, M. I. Gimenez, and V. Guzman, "Direct torque control of induction motors using fuzzy logic with current limitation," in Industrial Electronics Society, 2005. IECON 2005. 31st Annual Conference of IEEE. IEEE, 2005, pp. 6-pp.

[2] Y. Hu, L. Zhong, M. Rahman, K. Lim, Y. Xu, M. Rahman, and A. Bhuiya, "Direct torque control of an induction motor using fuzzy logic," in Electrical and Computer Engineering, 1997. Engineering Innovation: Voyage of Discovery. IEEE 1997 Canadian Conference on, vol. 2. IEEE, 1997, pp. 767-772.

[3] F. Sheidaei, M. Sedighizadeh, S. Mohseni-Zonoozi, and Y. Alinejad-Beromi, "A fuzzy logic direct torque control for induction motor sensorless drive," in Universities Power Engineering Conference, 2007. UPEC 2007. 42nd International. IEEE, 2007, pp. 197-202.

[4] R. Khanna, M. Singla, and G. Kaur, "Fuzzy logic based direct torque control of induction motor," in Power \& Energy Society General Meeting, 2009. PES'09. IEEE. IEEE, 2009, pp. 1-5.

[5] B. N. Kar, K. Mohanty, and M. Singh, "Indirect vector control of induction motor using fuzzy logic controller," in Environment and Electrical Engineering (EEEIC), 2011 10th International Conference on. IEEE, 2011, pp. 1-4.

[6] M. A. Mannan, T. Murata, J. Tamura, and T. Tsuchiya, "Fuzzy-logic-based self-tuning pi controller for speed control of indirect field-oriented induction motor drive," in SICE 2004 Annual Conference, vol. 1. IEEE, 2004, pp. 466-470.

[7] J. L. Afonso, J. Fonseca, J. S. Martins, and C. A. Couto, "Fuzzy logic techniques applied to the control of a threephase induction motor," in Industrial Electronics, 1997. ISIE'97., Proceedings of the IEEE International Symposium on. IEEE, 1997, pp. 1179-1184.

[8] E. Purwanto, M. Daniel, G. Prabowo, A. Rofig et al., "Simulation of the application fuzzy logic controller in 3 phase induction motor speed control by selecting membership function parameter," in TENCON'02. Proceedings. 2002 IEEE Region 10 Conference on Computers, Communications, Control and Power Engineering, vol. 3. IEEE, 2002, pp. 20502052.

[9] E. Gur and Z. Zelavsky, "Retrieval of rashi semi-cursive handwriting via fuzzy logic," in Frontiers in Handwriting Recognition (ICFHR), 2012 International Conference on. IEEE, 2012, pp. 354-359.

[10] I. El-Arabawy, M. Rizk, and H. Khaddam, "The effect of membership functions in fuzzy systems on the stability region," in Electronics, Circuits and Systems, 2000. ICECS 2000. The 7th IEEE International Conference on, vol. 1. IEEE, 2000, pp. 546-549.

[11] M. S. M. Aras, S. Bin Syed Salim, E. C. S. Hoo, I. Razak, and M. Hendra Bin Hairi, "Comparison of fuzzy control rules using matlab toolbox and simulink for dc induction motorspeed control," in Soft Computing and Pattern Recognition, 2009. SOCPAR'09. International Conference of. IEEE, 2009 , pp. 711-715.

[12] J. Gayathri Monicka, N. Guna Sekhar, and K. Ramash Kumar, "Performance evaluation of membership functions on fuzzy logic controlled ac voltage controller for speed control of induction motor drive," International Journal of Computer Applications, vol. 13, no. 5, pp. 8-12, 2011.

[13] B. Kimiaghalam, M. Rahmani, and H. Halleh, "Speed \& torque vector control of induction motors with fuzzy logic controller," in Control, Automation and Systems, 2008. ICCAS 2008. International Conference on. IEEE, 2008, pp. 360-365.

[14] J. J. Saade and H. B. Diab, "Defuzzification methods and new techniques for fuzzy controllers," Iranian journal of electrical and computer engineering, vol. 3, no. 2, p. 161, 2004 . 